Abstracta Iranica Abstracta Iranica

Revue bibliographique pour le domaine irano-aryen

Volume 42-43 | 2021

Comptes rendus des publications de 2019-2020

\title{
Koichi Matsuda. "Comparing the Depictions of the Mongol Courts Created in the Yuan and the Ilkhanate"
}

\section{Simon Berger}

\section{(2) OpenEdition}

Journals

Édition électronique

URL : https://journals.openedition.org/abstractairanica/53867

DOI : 10.4000/abstractairanica.53867

ISSN : 1961-960X

Éditeur :

CNRS (UMR 7528 Mondes iraniens et indiens), Éditions de l'IFRI

Référence électronique

Simon Berger, "Koichi Matsuda. "Comparing the Depictions of the Mongol Courts Created in the Yuan and the Ilkhanate" ", Abstracta Iranica [En ligne], Volume 42-43 | 2021, document 43, mis en ligne le 30 décembre 2021, consulté le 14 décembre 2022. URL : http://journals.openedition.org/ abstractairanica/53867 ; DOI : https://doi.org/10.4000/abstractairanica.53867

Ce document a été généré automatiquement le 14 décembre 2022.

Tous droits réservés 


\title{
Koichi Matsuda. "Comparing the Depictions of the Mongol Courts Created in the Yuan and the Ilkhanate"
}

\author{
Simon Berger
}

\section{RÉFÉRENCE}

Koichi Matsuda. "Comparing the Depictions of the Mongol Courts Created in the Yuan and the Ilkhanate" in T. May, D. Bayarsaikhan, C. P. Atwood (eds.). New Approaches to Ilkhanid History. Leyde : Brill, 2020, p. 176-197.

1 L'A. analyse l'une des scènes de cour mongole représentées sur une double page du célèbre album Diez, remontant au début du XIV siècle (Staatsbibliothek zu Berlin Preußischer Kulturbesitz, Orientabteilung, Diez A., f. 70, p. 11, nº 1 et f. 70, p. 21 ; voir Julia Gonnella, Friederike Weis, Christoph Rauch (eds.). The Diez Albums: Contexts and Contents. Leyde : Brill, 2017) en regard notamment du Huangyuan chaoyi zhi tu 皇元朝儀 之圖 (le "Diagramme du rituel de cour yuan»), une description de la cour des empereurs mongols de Chine contenue dans le Shilin guangji 事林廣記, une encyclopédie de l'époque des Song régulièrement remaniée sous les Yuan. Ainsi que de diverses autres sources chinoises. Il montre ainsi que la représentation picturale qui illustrait un exemplaire du Jāmi at-tavārïkh de Rashīd ad-Dīn, et qui dépeint donc certainement la cour des Ilkhans d'Iran (même s'il n'est pas à exclure qu'il s'agisse d'une représentation de la cour du Qa'an de Chine), correspond assez précisément au rituel de cour des Yuan, qu'il s'agisse de la position des hommes, des femmes et des objets, ou des libations offertes au souverain. L'A. identifie notamment sur la représentation picturale les masses d'armes des officiers de la garde, objets appelés en chinois guduo 骨朵, dont l'usage remontait à la dynastie khitan des Liao. Il faut donc en 
conclure que ces documents illustrent, de part et d'autre de l'Eurasie, des pratiques auliques similaires, remontant à une origine mongole (voire plus généralement steppique) commune. L'article est accompagné des reproductions en couleur des pages concernées de l'album Diez et du Huangyuan chaoyi zhi tu, de trois diagrammes permettant d'interpréter l'arrangement spatial de la cour mongole, ainsi que d'une planche détaillant le guduo placée à côté de deux détails tirés de l'illustration du Jāmi at-tavārikh à des fins de comparaison.

\section{AUTEURS}

\section{SIMON BERGER}

Doctorant EHESS, CETOBAC, Paris 